\title{
"You Must Adhere Strictly to the Time and Days of Intake": Medical Advice and Negotiations of Medical Authority in Nigerian HIV Consultations*
}

\author{
Eniola Boluwaduro (Ede, Nigeria)
}

\begin{abstract}
Using the methodology of conversation analysis, this paper examines the practice of offering medical advice and its implication for negotiations of medical authority in Nigerian HIV consultations. Analyses of ninety treatment recommendation sequences from seventy audio-recorded interactions between doctors and HIV-positive patients reveal that doctors issue instructions as a form of medical advice on patients' adherence to medical recommendations. During the advisory interactions, patients are held accountable for maintaining medical wellness, although the doctors' reasons for offering medical advice, and the turn design and sequential distribution of the advice-giving sequence indicate that advice serves to enact authoritative roles. The findings are a counter-balance to the position, in existing conversation analysis research, that patients' actions palliate medical authority. This paper calls for a broader conceptualisation of "adherence" and "medical authority" within medical institutional settings.
\end{abstract}

\section{$1 \quad$ Introduction}

The research on medical authority in medical sociology and medical conversation analysis presents two distinctive arguments. On the one hand, researchers state that doctors' paternalistic approach is predominant in medical encounters, thus constituting the underlying cause of patients' non-participative behaviours during consultations (cf. Mishler 1984; Roter/Hall 2006). Although perceptions of the doctor's authority vary considerably across cultures, for example in Spanish and British medical consultations (Hernández-López 2011), the paternalistic dominance implies that doctors' professional stance limits patient-centred work, as evident in situations where doctors' authoritative roles may create difficult encounters (cf. McPherson/Byng/Oxley 2014). On the other hand, findings indicate that doctors work to withdraw some of their authority, thereby encouraging patients to, for example, participate more in the consultations by answering "more than the question" during medical history taking (Stivers/Heritage 2001) or requesting for a diagnostic test (cf. Gill 2005; cf. Peräkylä 1995).

\footnotetext{
* The author appreciates the comments of two anonymous reviewers and Stephen Boluwaduro on an initial draft of this paper. This research was completed during the author's visit to the University of Oxford as a visiting fellow with Africa Oxford Initiative (AfOx), in collaboration with The Oxford Research Centre in the Humanities (TORCH). The author is grateful to AfOx-TORCH for offering a platform to complete this research.
} 
The notion of medical authority is more evident in the conversation analysis work on treatment recommendations. As Stivers (2017: 9) assert, physicians "adopt a position of greater epistemic and deontic authority relative to the patient" when recommending treatment, although "the action of the recommendation, shaped by the specific contingencies of the medical encounter, may encode this authority to a variable extent.". The authors observe that a mixture of deontic and epistemic authority means that pronouncements such as "I'm going to put you on X." directly convey medical authority in treatment recommendations. However, other recommendation formats such as suggestions (e. g. "We can give you X to try."), maintain greater epistemic authority over the recommendation, although it relinquishes deontic authority (cf. ibid. 2017: 5). Other ways to achieve such joint decision-making between physicians and patients is by "offering patients choices", even in situations where such choices may convey physicians' preferences, such as addressing patient resistance (Toerien 2011). Further, "optionlisting - relative to recommending" (Toerien/Shaw/Reuber 2013: 873) may be preferred for treatment recommendations. This is owing to the epistemic differences between the two practices, and differences in slot positioning for the patients' responses. Thus, an examination of the way treatment decision-making is initiated by clinicians is essential for understanding patients' actions and physicians' authority: physicians may work in favour of, or against shared decision-making during treatment recommendations. These different perspectives foreground the ways in which the interactional circumstances and the medical context(s) influence shared decision-making between doctors and patients, making it relevant for patients to either establish their communicative roles in medical encounters (cf. Heritage/Robinson 2006), "co-construct" (Maynard 2012) medical activities, or become non-participative.

In line with these arguments, this paper examines doctor's practices of offering medical advice on patients' adherence to medical recommendations in Nigerian HIV consultations. Although the HIV infection is no longer fatal, its treatment depends on the regular and consistent intake of anteretroviral treatment (ART). Thus, the research focus is especially topical, given that in Nigerian HIV clinics, interactions are centred on care and support for the patients and these goals are accomplished when patients periodically attend the routine consultations and adhere to treatment regimens. Further, studies on the contextual features of doctor-patient interactions in Nigeria (e. g. interactive strategies, cf. Adedoyin 2012; Odebunmi 2013) has neglected the organisation of interactional practices and actions in Nigerian HIV interactions (apart from Boluwaduro 2017, 2018; cf. Boluwaduro/Groß 2019; Boluwaduro (forthcoming)) and the ways by which doctors enact authoritative roles, regardless of patients' responsive actions, when recommending treatment. In addition, an extensive study on the epidemiology of HIV/AIDS and HIV consultations has been conducted mainly in regions outside the Global South, although there are some studies regarding HIV/AIDS consultations in South Africa. In the Western region, the research by Peräkylä, Silverman, and Bor is a case in point. The authors published extensive reports of their study on communication between medical practitioners and HIV/AIDS patients in primary care visits in some clinics in the United Kingdom (cf. Silverman/Peräkylä 1990; Peräkylä/Silverman 1991; cf. Peräkylä/Bor 1990; Silverman/Peräkylä/Bor 1992; Peräkylä 1995). They explore HIV/AIDS counselling sessions and "how professionals and clients organize their talk in relation to the delicate issues" (Silverman/Peräkylä 1990: 293). Conversely, the present study explores negotiations of 
medical authority - differing significantly in its research focus, institutional context, cultural settings, and participants' selection. This paper argues that the reason for offering medical advice, and the turn designs of advice-giving sequences, are insightful factors for understanding how medical authority is negotiated in Nigerian HIV consultations. Implications of these findings are related to medical practice in Nigeria.

\section{Advice-Giving in Medical Consultations}

Advice-giving is a central practice in several types of interactions. The pragmatic understanding of the speech acts suggests that advice means "telling you what is best for you" (Searle 1969: 67). In professional-client encounters, advice-giving is unidirectional; it is normatively initiated by the professional to the client (cf. Kawashima 2010; Kiuru et al. 2004). Thus, the conduct of the professional is taken as a point of departure for the exploration of this interactional practice, as is the tendency for understanding the different trajectories in institutional interactions (cf. Antaki 2011; Heritage/Lindström 2012). The initiation of advice, however, requires appropriate responsive actions, without which tension and conflict may arise between the participants in the encounters (cf. ibd.).

In medical and health-related settings, advisory interactions have been the focus of extensive research by linguists. Studies range from various contexts, including interactions between health visitors and first-time mothers in Britain (Heritage/Lindström 2012), HIV counselling (Silverman/Peräkylä/Bor 1992; Peräkylä 1995) and mediated interactions (Baker/Emmison/Firth 2005). The central arguments by these researchers indicate that certain factors influence participants' actions in advisory interactions, including the social contexts of the medical encounters (public or private), taboo topics (e.g., issues of sexuality, Silverman/Peräkylä/Bor 1992), the time constraints of the encounters, the interactional environment in which advice is introduced, the impact of societal and cultural ideologies, and epistemic (knowledge) and deontic (power) asymmetries between the doctor and patient. As Locher/Limberg (2012: 1) assert, it is not just the content of the advice that may influence perceptions of its force and appropriateness, but also the way it is communicated. In view of this argument, this paper investigates the communicative practice of advice-giving and its responsive actions in Nigerian HIV interactions.

\section{$3 \quad$ Data and Method}

The data is a corpus of seventy audio recordings of consultations between doctors and HIVpositive patients which was gathered at four outpatient clinics in Southwestern Nigeria between August and December 2015. Ten visits were made to the clinics to record interactions between doctors and patients. The participants consist of eight male doctors, two female doctors, and seventy patients. The recordings involve a minimum of two parties in each interaction. Due to the multilingual nature of the Nigerian society (cf. Boluwaduro 2019), there are at least, two languages in the interactions: Standard Nigerian English and Yoruba (the native language of the ethnic group in Southwestern Nigeria). Data were transcribed using Gesprächsanalytisches Transkriptionssystem (GAT 2), a system for transcribing talk-in-interaction compiled by German linguists (cf. Selting et al. 2011; see Appendix for details). 
The "lite" transcription was adopted for transcribing the data because audio files had background noises that made it impossible to do a more detailed transcription. The analytical method used is CA (for review cf. Atkinson/Heritage 1984; Drew/Heritage 1992; Heritage/Maynard 2006). Data collection for this study was officially approved by the local ethics and research committees of select clinics, and patients who participated in the study signed informed consents prior to the study. The seventy participating patients knew about the recordings and the researcher obtained their permission to publish the recordings. The data analysis is focused on the treatment recommendation sequence, with a total of ninety (90) treatment recommendation sequences as sub-corpus. Thus, each consultation consists of at least a minimum of one treatment recommendation sequence. Although boundaries between the treatment recommendation sequences and other sequences are fluid, the analyses (as shown in the extracts) specifically focus on participants' discussions about drug use, regular clinic visits, and CD4 count cell tests. These topics reflect the participants' references to certain situations and contexts within the clinic settings: the notion of "treatment" at the clinic transcends the patients' use of the required drugs. It also entails the monitoring of patients' adherence ART and non-ART medications and their compliance with other medical recommendations (including regular clinic visits and CD4 count cell tests). Taken together, these expectations make up the topics discussed during treatment discussions and are used by doctors to determine patients' willingness to take actives role in adhering to the treatment routines.

\section{$4 \quad$ Results}

The proceeding analyses show that medical authority is reflected both in the justifications for offering advice and in the turn design of the advice-giving sequence. Results show that the doctors issue medical advice that specifically enforces patients' adherence to medical recommendations. Thus, triggering adherence in the patients forms the primary reason for offering advice. In a second step, the analysis explores the turn designs of the advice-giving sequence and its turn properties. Advice is issued in response to patients' deteriorating medical health and these advice-giving sequences are organised in such a way that patients' agency in shared-decision making on the treatment routine is not recognised. The doctors' directives are made relevant with turns which do not allocate proceeding turns for patients' responses. Advice is also issued as an uptake on patients' dispreferred responses, and mitigated by accounts. These patterns are prevalent in eighty percent $(80 \%)$ of the sub-corpus (72 sequences). The results will be illustrated by drawing on different consultations.

\subsection{The Reasons for Offering Advice on the Treatment Routine}

As a first overarching observation, doctors assert authoritative roles by issuing instructions based on evaluations of patients' good medical health and compliance with medical recommendations. In this context, the relationship between the activity of "doing advice" and medical authority touches on the management of interactional goals (cf. Spencer-Oatey 2008). As will be shown subsequently, the specific interactional tasks set by the doctor are completed when the doctor has persistently instructed the patient on health-related behaviours. 


\subsubsection{Advice Based on Medical Health}

Medical health-related advice occurs when patients are ill from opportunistic infections. As indicated in extract 1 , the patient is not thriving medically. She is thus instructed to take various medical tests and use prophylactic drugs - the patient had complained about a stomach ache, and her CD4 count is low (not shown in extract 1). The doctor, however, states that her stomach ache is probably caused by using painkillers (Alabukun) (cf. lines 01-09).

\section{Extract 1}

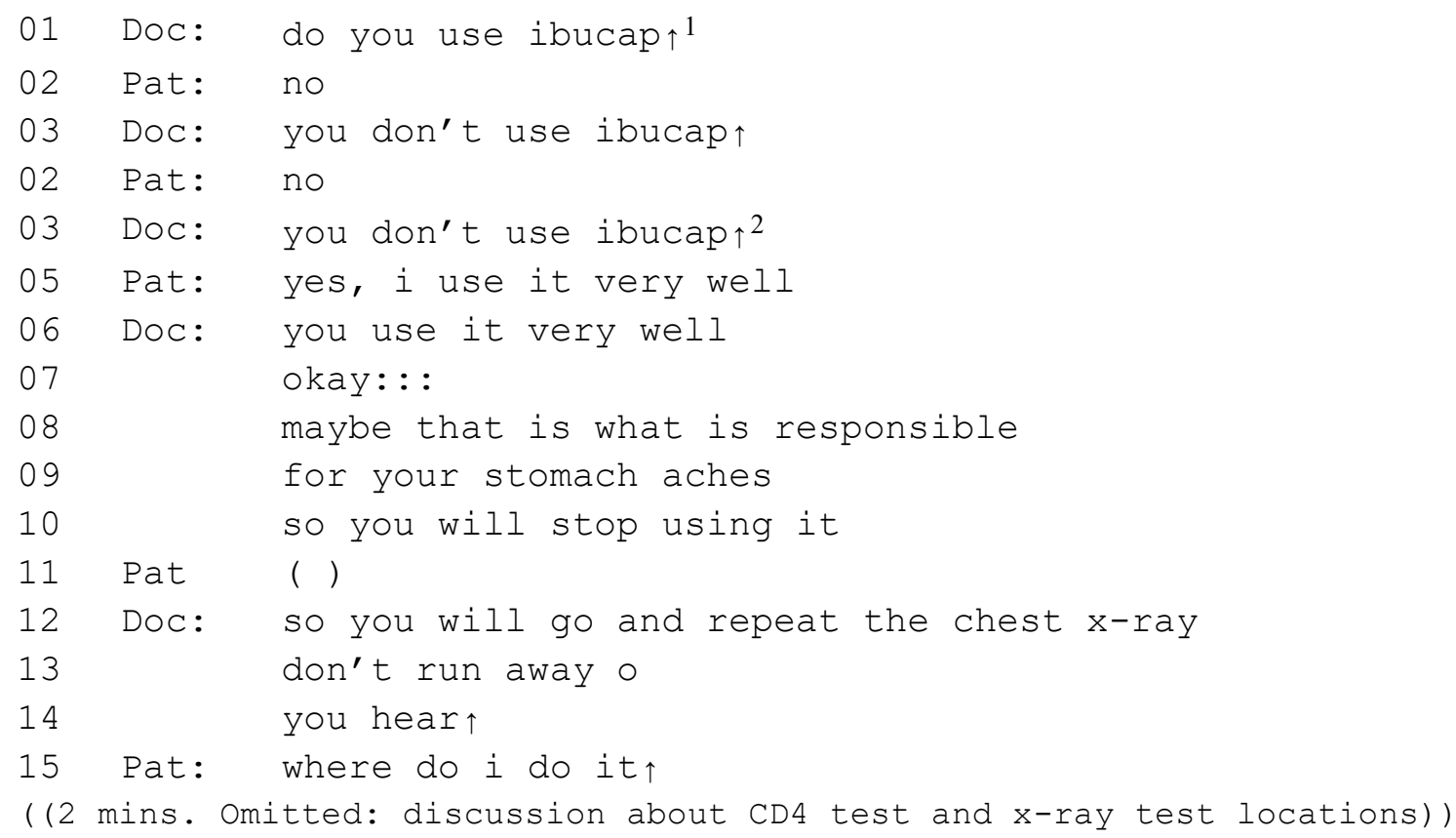

Subsequently, the patient is instructed to stop taking the painkillers "so you will stop using it" (line 10). In line 12, another turn is initiated which gives more instructions about conducting a chest x-ray. These instructions are substantiated and reinforced with what appears to be a selfinitiated self-repair that addresses the problem of hearing when the patient does not immediately respond, "you hear?". However, the interrogative form "you hear?" in Nigerian English calls for the listener's focused attention on the information being shared. It is often used during verbal exchanges between speakers with maximal social distance and hierarchical social relations (cf. Bamiro 1991). Thus, the extract shows that the doctor's instructions assert his role as the doctor while advocating for the patients' adherence to medical recommendation (cf. Heritage/Lindström 2012).

In another example (extract 2), medical authority is asserted through the doctor's instruction to the patient to purchase drugs outside the clinic: she had reported ill-health (not shown in extract 2) and will need to conduct certain tests before starting to receive the freely distributed ART at the clinic's pharmacy (lines 16-22).

\footnotetext{
${ }^{1}$ Ibucap is used for treating diverse types of pain.

2 Alabukun is an indigenous brand, produced and distributed widely in Nigeria. Often purchased by most Nigerians as an over-the-counter drug, it is an analgesic that works effectively for several purposes such as relieving migraine, backpain, toothache, and sore throat.
} 


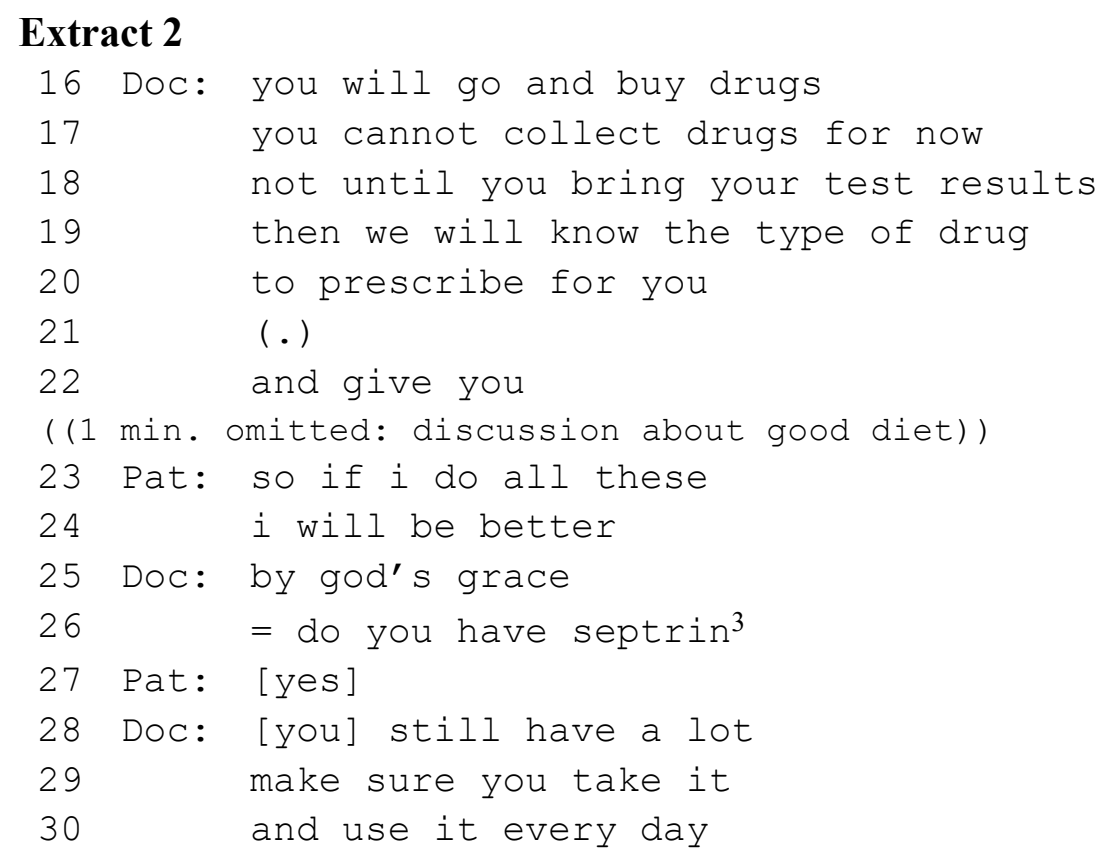

The patient's response shows that she expresses reservations about the effectiveness of the current treatment. Thus, she orients to the doctor's expertise and epistemic status and requests assurance of future wellness if she adheres to the doctor's instructions (lines 23-24). By requesting assurance, the patient displays knowledge of her medical health status but simultaneously shows that she does not have access to such medical knowledge (Gill 1998). The doctor, however, assures the patient of good medical health by leaning towards a religious reference "by god's grace" (line 25) and a medication-related concern (line 26). Through these references, the doctor claims autonomy and maintains the right to advise the patient on good medical health. His inference from the patient's "yes" in line 27 is further evident when the interaction proceeds with another instruction "Make sure you take it and use it every day" (lines 29-30). Thus, the doctor's advice responds to the information on medication (line 26) while also advocaing for the patient's good medical health (lines 29-30) (cf. Heritage/Lindström 2012 on instructions for advocacy and information).

\subsubsection{Advice on Health-Related Behaviour}

Uttering concerns relating to patients' health-related behaviour serves to establish medical authority. As shown in extract 3, the doctor employs the imperative forms to address a healthrelated behaviour - in lines 47-48, he asks about a previously prescribed ART and in line 49, he instructs the patient to use the drugs prescribed.

\section{Extract 3}

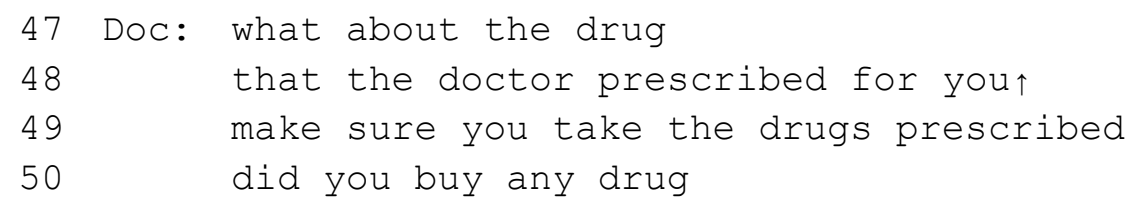

\footnotetext{
${ }^{3}$ Septrin is an antibiotic that is used to treat infections caused by bacteria. At the Nigerian HIV clinics, it is recommended as a part of the treatment routine. drugs.
} 
that looks as if its water inside ${ }^{4}$

52 Pat: that is usually inside water

53 Doc: hm: hm?

54 Pat: i didn't buy it

55 Doc: i will write it for you now

$56 \quad$ go and buy it

57 Pat: yes (.) write it [for me ]

58 Doc: [yes i have] written it

59 go and buy it and use it

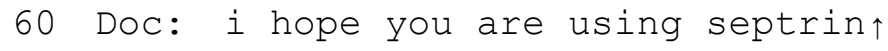

61 Pat: ehn: : i use septrin

62 Doc: okay (.) you use septrin

63 make sure you use it always $0_{--}^{-}$

Note that the doctor further requests to know about another type of drug that the patient may have bought (lines 50-53). Thus, when the patient offers a dispreferred turn by responding in the negative (line 54), an instruction follows "I will write it for you now, go and buy it" (lines 55-56). The patient's subsequent uptake on the instruction is cooperative - she accepts the recommended prescription and consents to follow the doctor's writing of the prescription "Yes, write it for me" (line 57). The doctor again, repeats his instruction as a "second saying" (Wong 2000) after confirming the prescription "Go and buy it and use it" (line 59). Such repetition of turn components contextualizes the given instruction as one that must be taken seriously and followed. Thereafter, he offers a statement of "hope" that the patient has been taking her Septrin, to which he receives a positive response, prefaced with an elongated "Ehn:::" ('yes'). The sequence closes with a question-intoned repeat (line 62) and a final instruction "Make sure you use it always $\mathrm{o}^{5}$ " (line 63). The doctor's final instructions call for a non-negotiated agreement on the treatment plan.

This same phenomenon is evident in extract 4. Here, the patient does not exercise her agency on shared treatment decision-making when she is adviced to adhere to the treatment routine. In lines $01-02$, the doctor asks about a previously prescribed drug. In response, the patient states that she has bought the drug (lines 03-04).

\section{Extract 4}

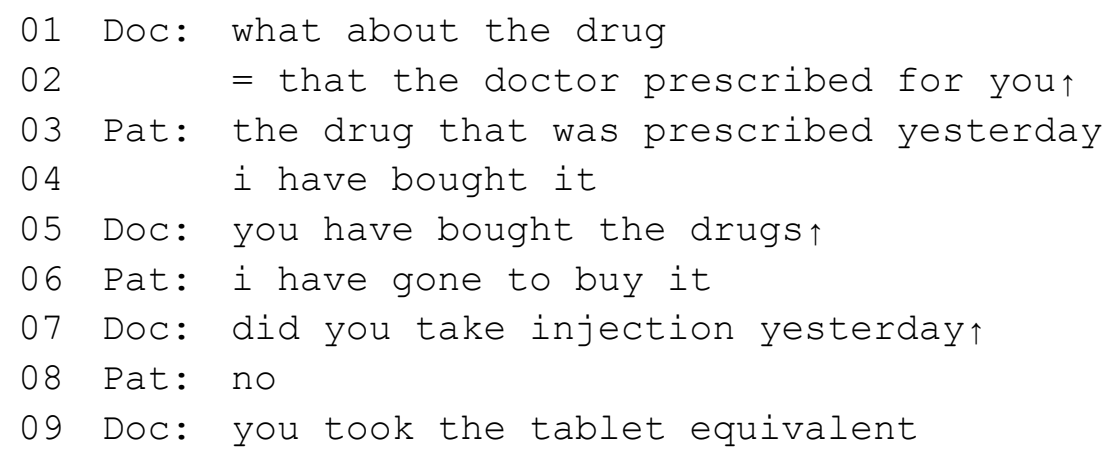

\footnotetext{
4 The doctor refers to an over-the-counter stomach gas remedy.

5 In Nigerian English usage, the discourse marker "o" secures the recipient's attention. It constitutes the beginnings and endings of conversation and functions to secure attention, agreement and solidarity with the listener (Enyi 2015: 42-53).
} 


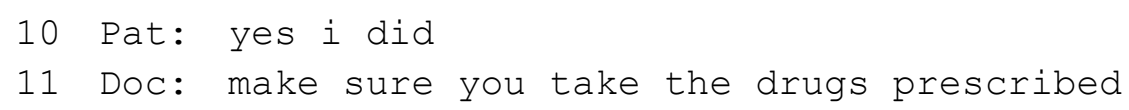

What follows is a question-intoned repeat that locates a specific part of the previous turn as a trouble source that needs to be clarified in terms of understanding "You have bought the drugs?" (line 05). The patient then confirms that she bought the drug "I have gone to buy it" (line 06). The doctor further asks about a previously prescribed injection, and he receives a dispreferred "no" (lines 08). In the next turn, the patient confirms that she uses the tablet equivalent of the drug (line 09). In response, the doctor's instruction on drug use is repeated for emphasis (line 11). What is evident here is that advice is used to direct the course of a future event relating to adherence to medical recommendations. These advice-giving sequences are designed as already situational upon the need to enforce compliance on the path of the patient. And in return, the patient does not contest the doctor's authority.

\subsection{Advice on the Treatment Routine - The Turn Designs}

A second overarching observation indicates that doctors establish medical authority through the turn design of the advice-giving sequence. Advice is issued with no allocation for patients' responses to pre-advice turn-units. Advice is also issued as an uptake on patient's dispreferred responses, and mitigated by accounts.

\subsubsection{No Allocation for Responses to Pre-Advice Turn-Units}

Several interactional mechanisms operate to constrain speakers' turn sizes, most of which presupposes the possible completion of a turn-constructional unit (TCU). A speaker's ability to gauge the end of a TCU determines the point at which the next speaker speaks, and if not, anyone may self-select; or the prior speaker may continue (Schegloff 2011). If the prior speaker continues, the continuation may be built as more of an "increment" (Schegloff 1996). In situations where the prior speaker increases his turn at the point of an apparent completion of a TCU, then the activity being done in the turn is not yet complete and vice versa (Schegloff 2011). This turn-taking device is evident in extract 5. Here, the patient's apparent good medical health is evident when the doctor instructs her to visit a Prevention of Mother to Child Transmission (PMTCT) centre (lines 26-35). She had previously mentioned no complaints and has a normal CD4 count test result (lines 36-42).

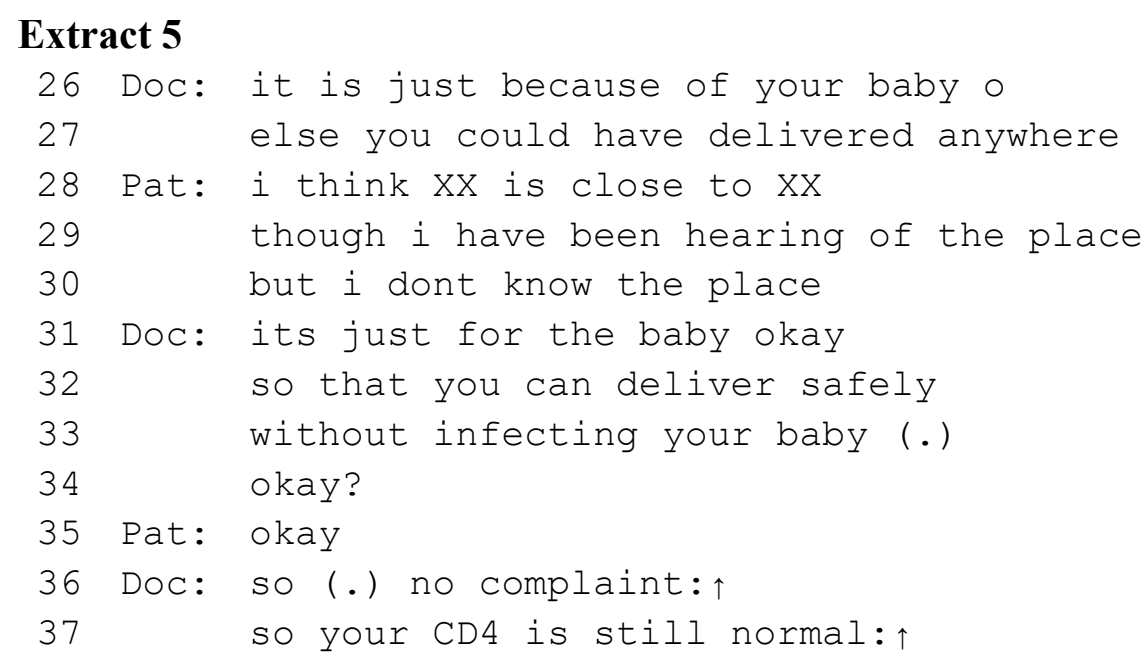




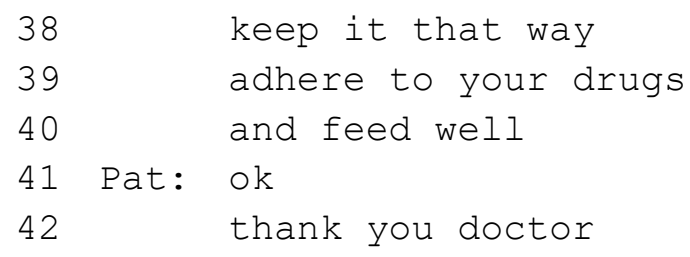

Thus, the doctor first confirms that the patient had conducted the required CD4 count cell volume tests and had a normal result (line 37) before instructing that she "Keep it that way" (line 38), adhere to her drugs and feed well (lines 39-40). The initial assessments in lines 36 and 37 are uttered with small pitch up-steps at the turn-final endings, indicating that an increment is projected at a next turn (the initiation of advice) and that the TCU of the current activity (assessment) is not yet complete. Building on this projection, the doctor then uses the imperative word form "adhere", a directive which suggests that the patient should refrain from negotiating or jointly making decisions regarding the recommended treatment. Thus, the instructions are uttered in multi-unit turns with no allocation for the patient's response at the completion of pre-advice turn units. Consequently, when the patient responds with a minimal token "ok" (line 41) and a statement of gratitude "thank you doctor" (line 42), she orients to the deontic force of the doctor's instructions by accepting his authority and role as the health-care provider.

Extract 6 shows another example. Here, it is stated that the pregnant patient receives alternative care at a Local Herbal Centre (LHC) (line 59). The patient is thus advised to take some tests (line 64).

\section{Extract 6}

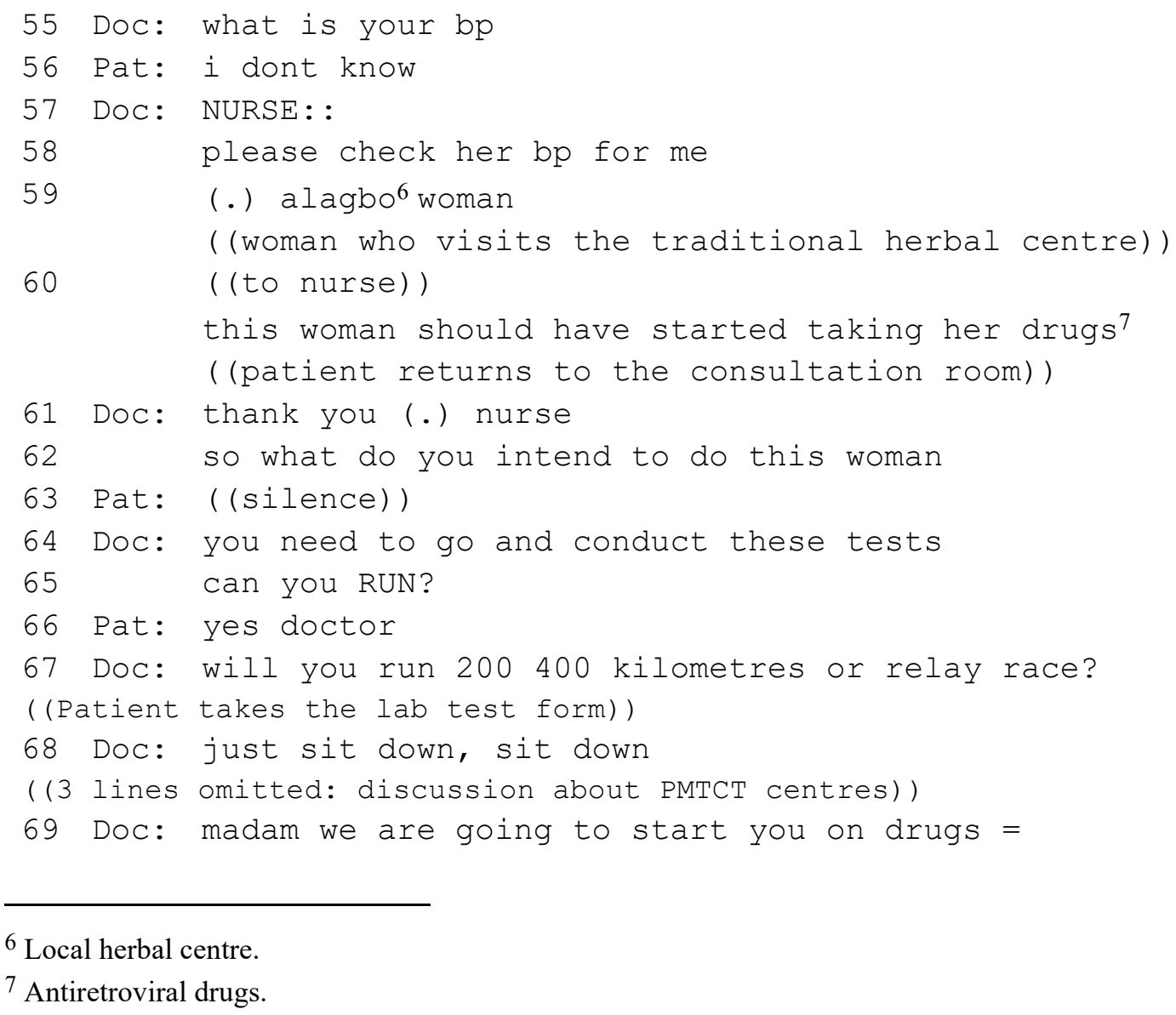




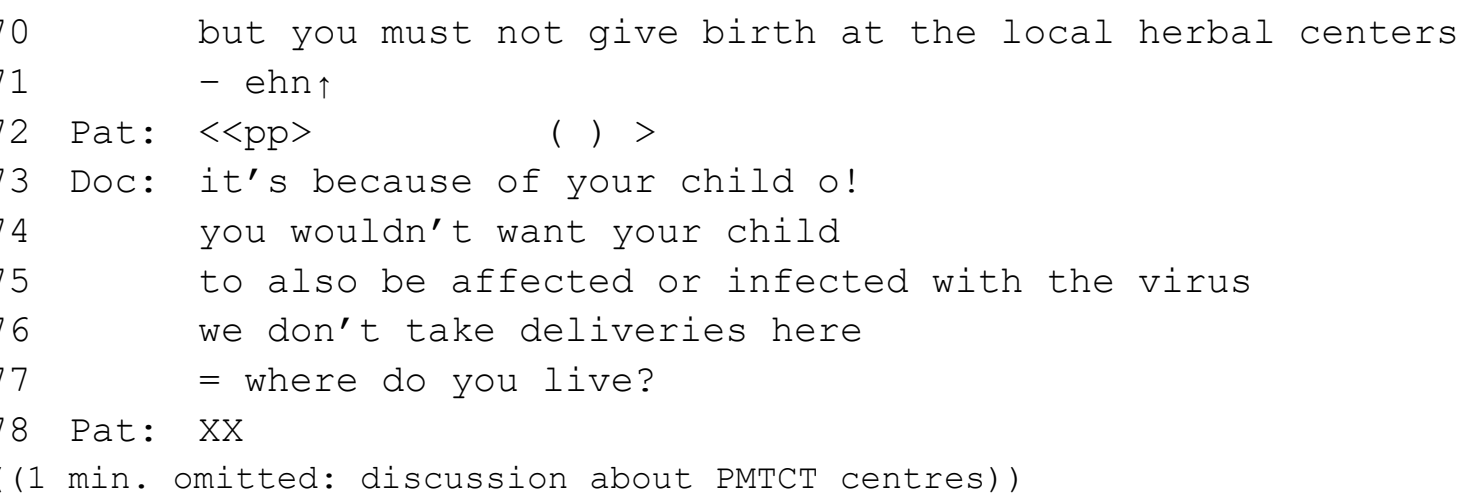

With a follow-up statement "Madam we are going to start you on drugs" (line 01), which Stivers et al. (2017: 2) refer to as "pronouncements", the doctor recommends that the patient starts to receive her drugs at the designated PMTCT centre. However, the pronouncement is followed by an advice not to give birth at the LHC (line 70), and a question marker ehn? ('ok?') (line 71). Although the doctor offers an explanation that accounts for his advice (lines 73-76), the patient is offered no opportunity to share in the decision-making process on the recommended treatment. Note that she is not allocated a turn for reaction(s) to the doctor's explanations (evidence that the activity of "doing explanation" is not relevantly complete) before the interaction moves on to other routine concerns (lines 77-78).

\subsubsection{Advice as Uptakes on Dispreferred Responses}

The issuing of advice in the imperative formats occurs when a doctor offers an uptake on a patient's dispreferred response. This observation is evident in extract 7: the doctor describes what the patient will do in the future concerning conducting a CD4 count test (test description not shown in extract 7). At line 01 , the doctor specifies with a deictic phrase "this test", and in line 02, an instruction is given "you will go and do it". After a short break (line 03), the patient offers a reason why the doctor's advice may be difficult to follow.

\section{Extract 7}

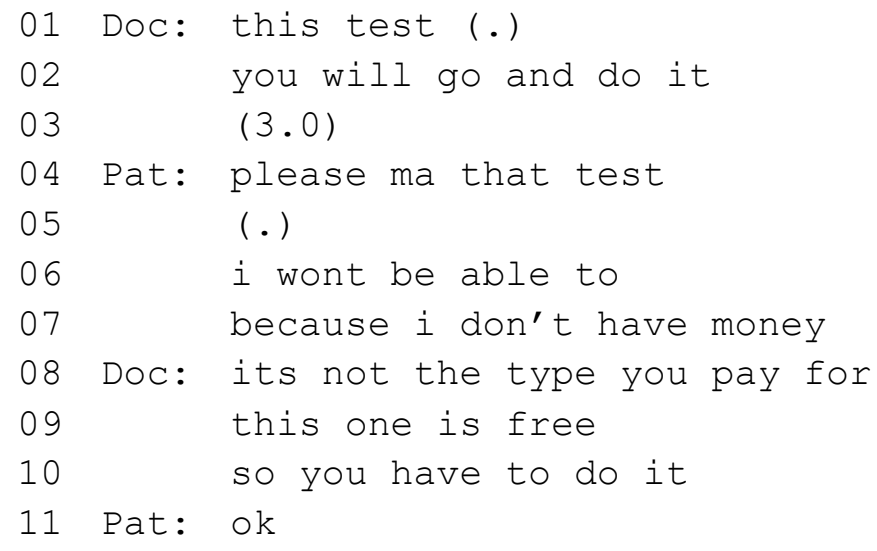

The patient's turn is designed with the lexical choice "please" in the turn initial, and an honorific term "ma". The use of the honorific term is a cultural reflection which suggests that she recognises the doctor's superiority and professional authority (cf. Boluwaduro 2018). She therefore appeals to him about a possible decision to disobey the instruction about the said test, on accounts of monetary challenges. This prefacing is followed by an account that stipulates a financial problem (lines 06-07). However, the doctor clarifies the financial implication of the 
test by informing that the test is free and must be done (lines 08-10). Consequently, the doctor's clarification eliminates the projection of an "action-type dispreferred response" (Sidnell 2010: 106) and compels the patient to comply, while the patient's "ok" (line 11) orients to the deontic force behind the projected action (i. e. an instruction to obey). The patient's responses show that in the event of a refusal to align with the actions projected by the doctor's advice, the doctor's medical authority is still maintained. Thus, her refusals are hedged through an appeal to the doctor's authority. This places her in a subordinate role as the receiver of an action.

Similarly, in extract 8, the doctor communicates in the Yoruba language and prescribes a future action for the patient regarding drug intake: "These are the drugs you will ingest" (line 05), "buy them at the pharmacy" (line 06).

\section{Extract 8}

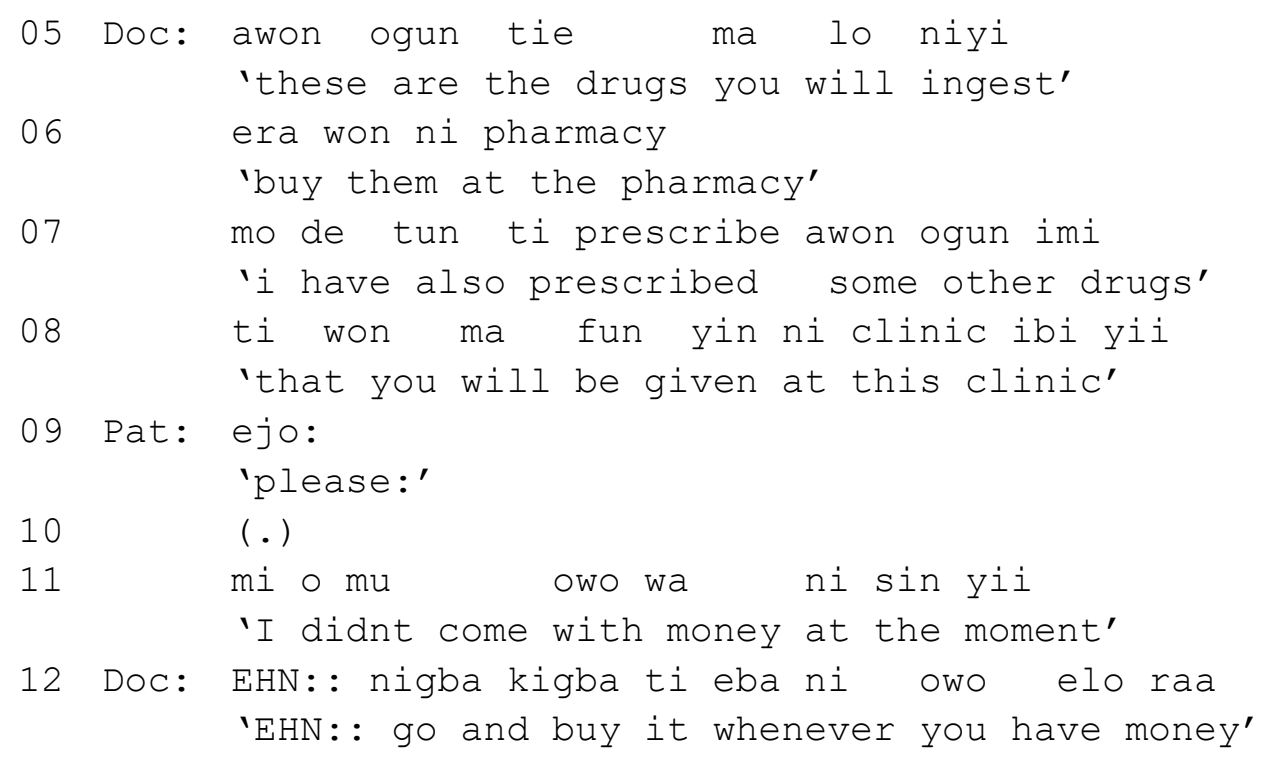

On the surface, one may posit that nonadherence has not been made relevant completely and cannot be established from this consultation. However, note that in response to being given prescription slips with the instruction for its use, the patient announces a possible rejection of the instruction by prefacing her turn with a "please" (line 09) and after a short pause, accounting for her dispreferred turn (line 11). On the doctor's path, he aligns with her announcement, although prefacing his response with an elongated assessment "Ehn ('Well') ...go and buy it whenever you have money" (line 12). The patient's dispreferred response is contextualized and constituted by how the instruction is oriented to. She responds to the directive at line 06 "Buy them at the pharmacy". Hence, her orientation to the preceding turn as an instruction which obligates her financially. Following the adjacency pair-rule, directives, as a social action, (in this case, an order) may be minimally completed when its recipients concede to the requested action without any verbal response (cf. Stevanovic/Peräkylä 2015). Here, however, the patient starts to utter a dispreferred response by offering a politeness cue with the lexical item "please" and hesitating before announcing her financial status.

\subsubsection{Advice Mitigated by Accounts}

Advice may also be given as pronouncements in a sequential environment that offers an extended explanation. In other words, the doctor's account strengthens the advice-giving, which 
leads to a proposal of treatment choices (cf. Houtkoop-Steenstra 1990 on accounting for proposals). As shown in extract 9, the doctor makes a pronouncement "We will give you drugs for a week and see how it goes" (lines 01 and 02) and after a brief pause (line 03), he instructs the patient to adhere to the prescribed drug use "you must adhere strictly to the time and days of intake" (lines 05-06), after which he begins an extended explanation about the importance of adherence (lines 08-26).

\section{Extract 9}

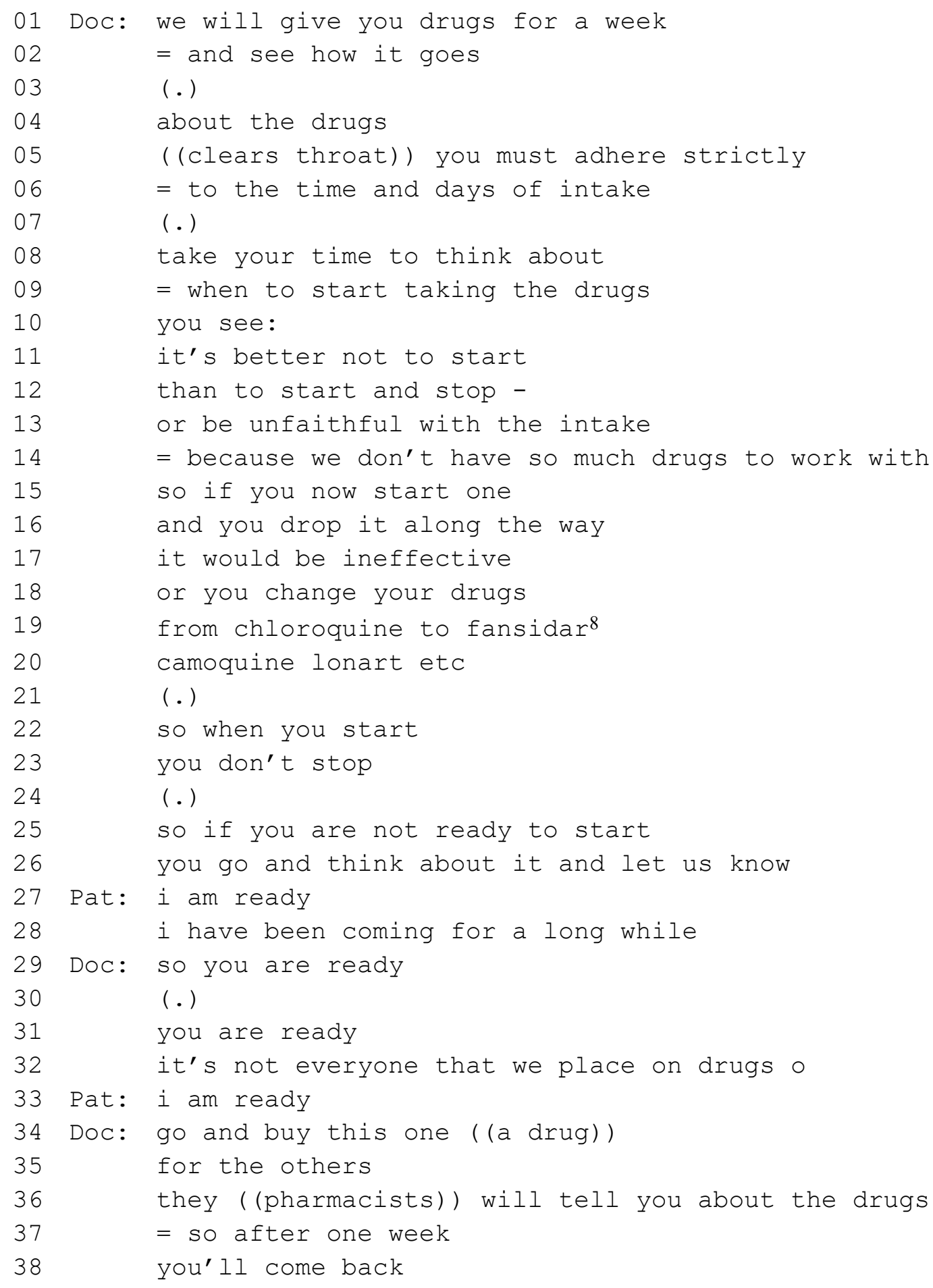

\footnotetext{
${ }^{8}$ Fansidar, Chloroquine and Lonart are anti-malaria drugs.
} 
In his explanation, the doctor suggests that the patient needs to consider starting the prescribed treatment routine (lines 08-09). Subsequently, he accounts for his advice by prefacing his explanations about the importance of drug use "you see" (line 10), and then, the extended account takes place within multi-unit turns. During this account, the patient orients to the doctor's trajectory by not offering a turn that interrupts the ongoing action but instead, she takes a turn at the end of the explanation when she is asked if she is ready to begin treatment "I am ready, I have been coming for a while now" (lines 27-38). To be sure that the patient's affirmation is processed epistemically, the doctor repeats her information "so you are ready" (lines 29 and 31) and then pursues a proper understanding of his suggestion with a relevant uptake of his suggestion "It's not everyone that we place on drugs o" (line 32). Afterward, the patient reaffirms that she is ready to start the treatment. She is then instructed to buy a certain drug (line 34), visit the pharmacist for advice on the next steps (lines 35-36), and return after a week (lines 37-38). It is evident here that the patient consents to the doctor's deontic authority to prescribe the needed drugs. Although the doctor mitigates the force of his advice by offering an explanation, he promises to withhold treatment if the patient will not follow his advice.

The practice of mitigating the deontic force of instructions is also evident in extract 10. In the beginning, the doctor formulates his treatment offers with a pronouncement (line 01-02).

\section{Extract 10}

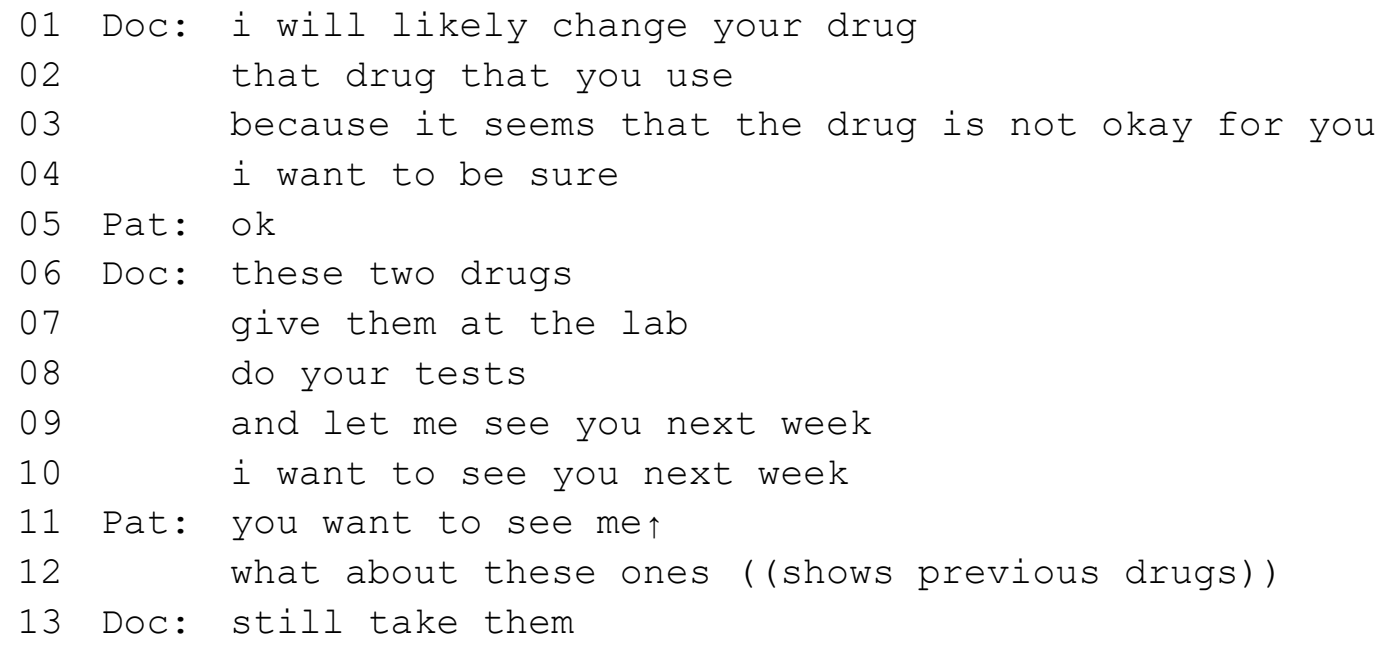

He then proceeds by offering an explanation that orients to his pronouncement as an epistemically modalized initiative about the inappropriateness of the patient's previous drugs: with "It seems ..." (line 03), he orients towards the knowledge that the previous drug was inappropriate and needed to be changed. On this premise, the doctor specifies the new drugs "these two drugs" (line 06), instructs her to get them at the pharmacist' laboratory (line 07) and requests to see her the following week (lines 09-10). Subsequently, the patient identifies his instruction as a trouble source with a question-intoned repeat (line 11) and asks about the previous drugs (line 12), while the doctor responds with another advice "Still take them" (line 13). In effect, the patient's request for clarification on the currently used ART (lines 11-12) indicates that the doctor's authority may be perceived as being weakened, especially because his decision on drug-change may be indecisive. However, the issuing of instructions indicate that his professional identity and role is maintained during the consultation. 


\section{Discussion}

This paper has examined the different designs of advice-giving sequences through which doctors negotiate medical authority in Nigerian HIV consultations. Findings indicate that hierarchical differences impact most on the advisory interactions and this is evident in the doctors' reasons for offering advice on the treatment routine, and the turn designs of the advicegiving sequence. Adherence-related trajectories are made relevant during treatment discussions and this sequence is characterised by the practice of giving instructions on drug use, regular CD4 count tests, and regular clinic visits. With utterances mostly structured as imperatives, this practice is often initiated by the doctors in the service of ensuring patients' adherence and good medical health. The focus on patients' adherence is crucial because it exemplifies the phenomenon of shared/non-shared decision-making between doctors and patients (cf. Stevenson et al. 2000), patients' expertise, and doctoring styles. It also advances discussions on the problem of compliance among patients who visit the clinic for chronic illnesses. The paper has shown that the ratification of medical authority occurs regardless of the possibility that patients may participate in the interactions; patients are mostly neglected in shared decisionmaking on treatment. Thus, patients' actions do not palliate medical authority, as asserted in conversation analysis research (cf. Peräkylä 1995; Stivers/Heritage 2001; Gill 2005; Stivers et al. 2017). Nonetheless, the offer of medical advice implies that patients are held responsible for maintaining medical wellness. This dual dynamic presents a complex situation but it lends credence to the medical care context.

In the HIV context, patients' adherence to medical recommendations is important because it has consequences on patients' overall medical well-being. Hence, both doctor and patient coconstruct responsibility for the patients' therapeutic behaviour while giving and receiving medical advice. Although evidence of medical authority and non-shared decision-making on treatment decisions exist in the consultations, there is also evidence that patients often could parse the deontic force of the doctors' instructions, and the doctors' professional role. Hence, patients submit their rights to shared decision-making on the treatment plans. This management of sociality rights and obligations between the participants imply that authoritative doctoring styles serve to obligate the patient in the successful outcome of treatment routines. Thus, there appears to be a meeting point between extreme forms of medical paternalism that jettisons the patient's agency, and communication that is patient-centered. Moreover, this paper suggests that the notions of "adherence" and "medical authority" need to be recontextualised. As the analyses show, a more holistic view of adherence as a multi-dimensional concept encompasses patients' overall compliance with medical recommendations. When this view is considered, it is assumed that doctors' medical authority may be exercised for the patients' best interest. 


\section{References}

Adedoyin, Eniola (2012). "Discourse-Pragmatic Features of Language Usage in Doctor-Patient Encounters in HIV/AIDS Clinics in Lagos State". Unpublished MA Thesis. University of Ibadan.

Antaki, Charles (2011): "Six kinds of applied conversation analysis". In: Antaki, Charles (ed.) Applied Conversation Analysis: Intervention and Change in Institutional Talk. Basingstoke, Palgrave Macmillan: 1-4.

Atkinson, John/Heritage, John (eds.) (1984): Structures of social action: studies in conversation analysis. Cambridge: Cambridge University Press.

Baker, Carolyn/Emmison, Michael/Firth, Alan (eds.). (2005): Calling for Help: Language and Social Interaction in Telephone Helplines. Amsterdam/Philadelphia: Benjamins.

Bamiro, Edmund (1991): “The social and functional power of Nigerian English". World Englishes 10/3: 275-286.

Boluwaduro, Eniola (forthcoming): "Patients' Compliance and Resistance to Medical Authority in Nigerian Clinical Encounters". Journal of Pragmatics.

Boluwaduro, Eniola (2017): “When last did you do CD4 count test?': Task-Based Opening Question Designs in Doctor/Patient Conversations about HIV". Ife Studies in English Language 13/2: 1-26.

Boluwaduro, Eniola (2018): (Non) Adherence in Doctor/Patient Interactions in Nigerian HIV Clinics. PhD Thesis. University of Bayreuth. epub.uni-bayreuth.de/3828/ [01.02.2020].

Boluwaduro, Eniola (2018): "Names as Cultural Reflections in Wole Soyinka's Death and the King's Horseman”. Journal of the Linguistic Association of Nigeria 21/1: 79-109.

Boluwaduro, Eniola (2019): "Ideology and Identity Construction in Ibibio Personal Names". Sociolinguistic Studies 13/2-3: 233-252.

Boluwaduro, Eniola/Groß, Alexandra (2019): “'How are you doing?' - 'Great!' Negotiating mundane, medical and moral dimensions of patients' wellbeing in opening sequences of German and Nigerian HIV consultations". In: Groß, Alexandra/Pech, Ramona/Vlassenko, Ivan (eds.): HIV/AIDS. Interdisziplinäre Perspektiven. Berlin, LIT Verlag.

Drew, Paul/Heritage, John (1992): Talk at Work: Interaction in Institutional Setting. New York: Cambridge University Press.

Enyi, Amaechi Uneke (2015): Style of Nigerian English Conversation: A discourse-stylistic analysis of a natural conversation. European Journal of English Language and Literature Studies, 3/4: 42-53.

Gill, Virginia (1998): 'Doing attributions in medical interaction: patients' explanations for illness and doctors' responses". Social Psychology Quarterly 61/4: 342-360.

Gill, Virginia (2005): "Patient 'demand' for medical interventions: exerting pressure for an offer in a primary care clinic visit”. Research on Language and Social Interaction 38/4: 45179.

Hernández-López, Maria de la O. (2011): "Negotiation strategies and patient empowerment in Spanish and British medical consultations". Communication and Medicine 8/2: 169-180.

Heritage, John/Maynard, Douglas (2006): "Introduction: analyzing interaction between doctors and patients in primary care encounters". In: Heritage, John/Maynard, Douglas (eds.) 
Communication in Primary Care: Interaction Between Primary Care Physicians and Patients. Cambridge, Cambridge University Press: 1-21.

Heritage, John/Robinson, Jeffrey (2006): “The structure of patients' presenting concerns: physicians' opening questions". Health and Communication 19/2: 89-102.

Heritage, John/Lindström, Anna (2012): "Advice giving - terminable and interminable : the case of British health visitors". In: Limberg, Holger/Locher, Miriam (eds.) Advice in Discourse Amsterdam, Benjamins: 169-194.

Houtkoop-Steenstra, Hanneke (1990): “Accounting for proposals". Journal of Pragmatics 14/1: 111-124.

Kawashima, Michie (2010): "Giving instruction on self-care during midwifery consultations in Japan”. Journal of Asian Pacific Communication 20/2: 207-225.

Kiuru, Päivi et al. (2004): "Advice-giving styles by Finnish nurses in dietary counseling concerning type 2 diabetes care". Journal of Health Communication 9: 337-354.

Locher, Miriam/Limberg, Holger (eds.) (2012): Advice in Discourse. Amsterdam: Benjamins.

Maynard, Douglas (2012): Good news, bad news, and affect: practical and temporal 'emotion work' in everyday life. In: Peräkylä, Anssi/Sorjonen, Marja-Leena (eds.) Emotion in Interaction. Oxford, Oxford University Press: 92-112.

McPherson, Susan/Byng, Richard/Oxley, Donna (2014): Heart Sink Depression in Primary Care: A conversation analysis study of multiple problem presentation. Health 18/3: 261-278.

Mishler, Elliot (1984): The Discourse of Medicine: Dialectics of Medical Interviews. Norwood: Ablex.

Odebunmi, Akin (2013): Multiple codes, multiple impressions: An analysis of doctor-client encounters in Nigeria. Multilingua, 32/3: 373-403.

Peräkylä, Anssi (1995): AIDS counselling: Institutional interaction and clinical practice. Cambridge: Cambridge University Press.

Peräkylä, Anssi/Bor, Robert (1990): “Interactional problems of addressing 'dreaded issues' in HIV-Counselling”. AIDS Care 2/4: 325-338.

Peräkylä, Anssi/Silverman, David (1991): "Owning experience: Describing the experience of other persons". Text - Interdisciplinary Journal for the Study of Discourse 11/3: 441-480.

Peräkylä, Anssi/Silverman, David (1991): "Reinterpreting Speech-Exchange Systems: Communication Formats in AIDS Counselling”. Sociology 25/4: 627-651.

Roter, Debra/Hall, Judith (2006). Doctors Talking with Patients / Patients Talking with Doctors $\left(2^{\text {nd }}\right.$ ed.). Westport: Praeger.

Schegloff, Emanuel (1996): "Turn organization: one intersection of grammar and interaction". In: Ochs Elinor/Schegloff, Emanuel/Thompson, Sandra (eds.), Interaction and Grammar. Cambridge, Cambridge University Press: 52-133.

Schegloff, Emanuel (2011): "Word repeats as unit ends". Discourse Studies 13/3: 367-380. doi.org/10.1177/1461445611402749.

Searle, John (1969). Speech Acts: An Essay in the Philosophy of Language. Cambridge: Cambridge University Press:67.

Selting, Margret et al. (2011): “A system for transcribing talk-in-interaction: GAT 2 translated and adapted for English by Elizabeth Couper-Kuhlen and Dagmar Barth-Weingarten". Gesprächsforschung - Online-Zeitschrift zur verbalen Interaktion 12: 1-51.

Sidnell, Jack (2010): Conversation Analysis. Oxford: Wiley-Blackwell. 
Silverman, David/Peräkylä, Anssi (1990): “AIDS Counselling: the interactional organization of talk about 'delicate' issues". Sociology of Health and Illness 12/3: 293-318.

Silverman, David/Peräkylä, Anssi/Bor, Robert (1992): "Discussing safer sex in HIV counselling: assessing three communication formats". AIDS Care 4/1: 69-82.

Spencer-Oatey, Helen (2008): "Face, (im)politeness and rapport". In: Spencer-Oatey, Helen (ed.) Culturally Speaking: Culture, Communication and Politeness Theory. London, Continuum: 11-47.

Stevenson, Fiona et al. (2000): "Doctor-patient communication about drugs: the evidence for shared decision making”. Social Science and Medicine 50/6: 829-840.

Stevanovic, Melisa/Peräkylä, Anssi (2015): "Experience sharing, emotional reciprocity, and turn-taking”. Frontiers in Psychology 6/450. doi: 10.3389/fpsyg.2015.00450.

Stivers Tanya et al. (2017): "Treatment recommendations as actions". Health Communication 33/11: 1335-1344.

Stivers, Tanya/Heritage, John (2001): "Breaking the sequential mold: answering "more than the Question" during medical history taking". Text 21/1-2: 151-185.

Toerien, Merran (2011): "Offering patients choices: a pilot study of interactions in the seizure clinic”. Epilepsy and Behavior 20/2: 312-320.

Toerien, Merran/Shaw, Rebecca/Reuber, Markus (2013): "Initiating decision-making in neurology consultations: 'recommending' versus 'option-listing' and the implications for medical authority". Sociology of Health and Illness 35/6: 873-890.

Wong, Jean (2000): "Repetition in conversation: A look at 'First and Second Sayings"'. Research on Language and Social Interaction 33/4: 407-424.

\section{Appendix}

\section{Transcription Convention}

[ ] [ ]

(.)

$(--)$

$(0.5) /(0.2)$

( )

$\rightarrow$

$=$

:

$::$

$:::$

,

;

$<<$ surprised $>$

$?$

SYLlable

?'

$<<\mathrm{pp}>$

$<<\mathrm{p}>$ overlap and simultaneous talk

micropause, estimated to $0.2 \mathrm{sec}$. duration

intermediate estimated pause of approx. $0.8 \mathrm{sec}$. duration measured pause of appr. 0.5/2.0 sec. duration

unintelligible passage

refers to a line of transcript relevant in the argument

fast, immediate continuation with a new turn or segment

lengthening, by about $0.2-0.5 \mathrm{sec}$.

lengthening, by about $0.5-0.8 \mathrm{sec}$.

lengthening, by about $0.8-1.0 \mathrm{sec}$.

rising to mid

falling to mid

$>$ interpretive comment with indication of scope smaller pitch upstep

focus accent

smaller pitch upstep to the peak of the accented syllable

$>$ pianissimo, very soft

$>$ piano, soft 


$\begin{array}{lll}<<\mathrm{l}> & > & \text { lower pitch register } \\ <<\text { all }> & > & \text { allegro, fast } \\ <<\mathrm{ff}> & > & \text { fortissimo, very loud } \\ <<\mathrm{f}> & > & \text { forte, loud } \\ \uparrow & \text { smaller pitch upstep } \\ \downarrow & \text { smaller pitch downstep } \\ <<:-)>\text { so }> & \text { smile voice } \\ ((\text { coughs })) & \text { non-verbal vocal actions and events } \\ ((\text { laughs })) & \text { description of laughter } \\ ((\text { unintelligible, appr. } 3 \mathrm{sec})) & \text { unintelligible passage with indication of duration } \\ ((\ldots)) & \text { omission in transcript }\end{array}$

